ISSN 2689-0852

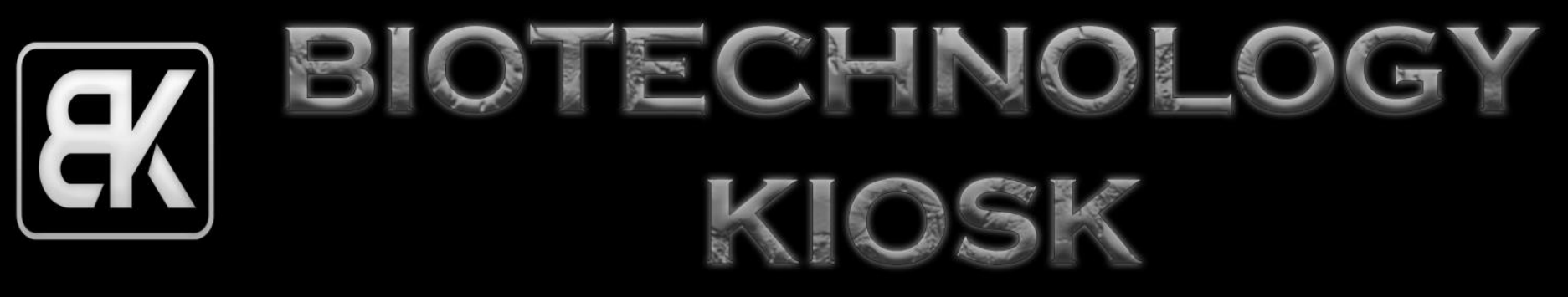

JUNE 2020

\title{
PARANOIA
}

\author{
VOLUME 2, ISSUE 6 \\ WWW.BIOTECHKIOSK.COM
}




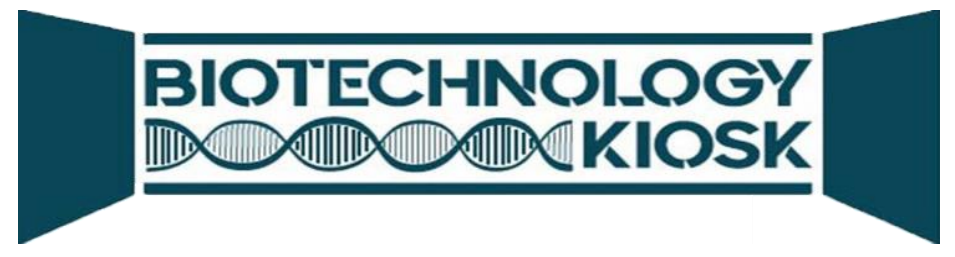

\section{Executive Publishers}

Megha Agrawal, PhD

(Biotechnology)

Publisher and Editor

Expertise:

Neuroscience, Stroke, Pharmacology, Toxicology, Microbiology and Molecular Biology

Email: megha@biotechkiosk.com meghaagra@gmail.com
Shyamasri Biswas, $\mathrm{PhD}$

(Biotechnology)

Publisher and Editor

Expertise:

Structural Biology, Enzyme Technology, and Protein Crystallography

Email: shyabiswas@biotechkiosk.com shyabiswas@gmail.com

\section{Editorial, Sales \& Circulation Office}

160 International Parkway

Suite 100-9, Heathrow

FL-32746, USA

Phone: 386-518-9411

Email: publisher@biotechkiosk.com

www.biotechkiosk.com

ISSN 2689-0852

One stop shop for all things biotech






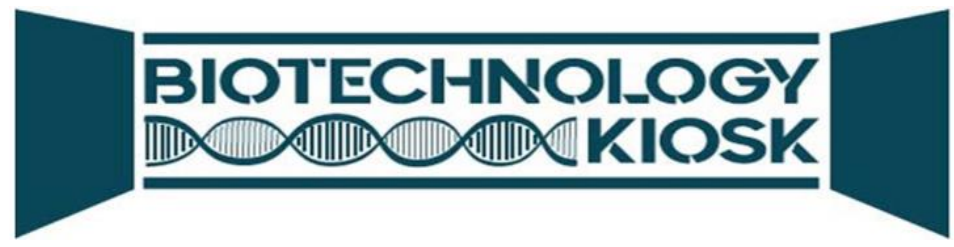

\section{From the Publisher's Desk}

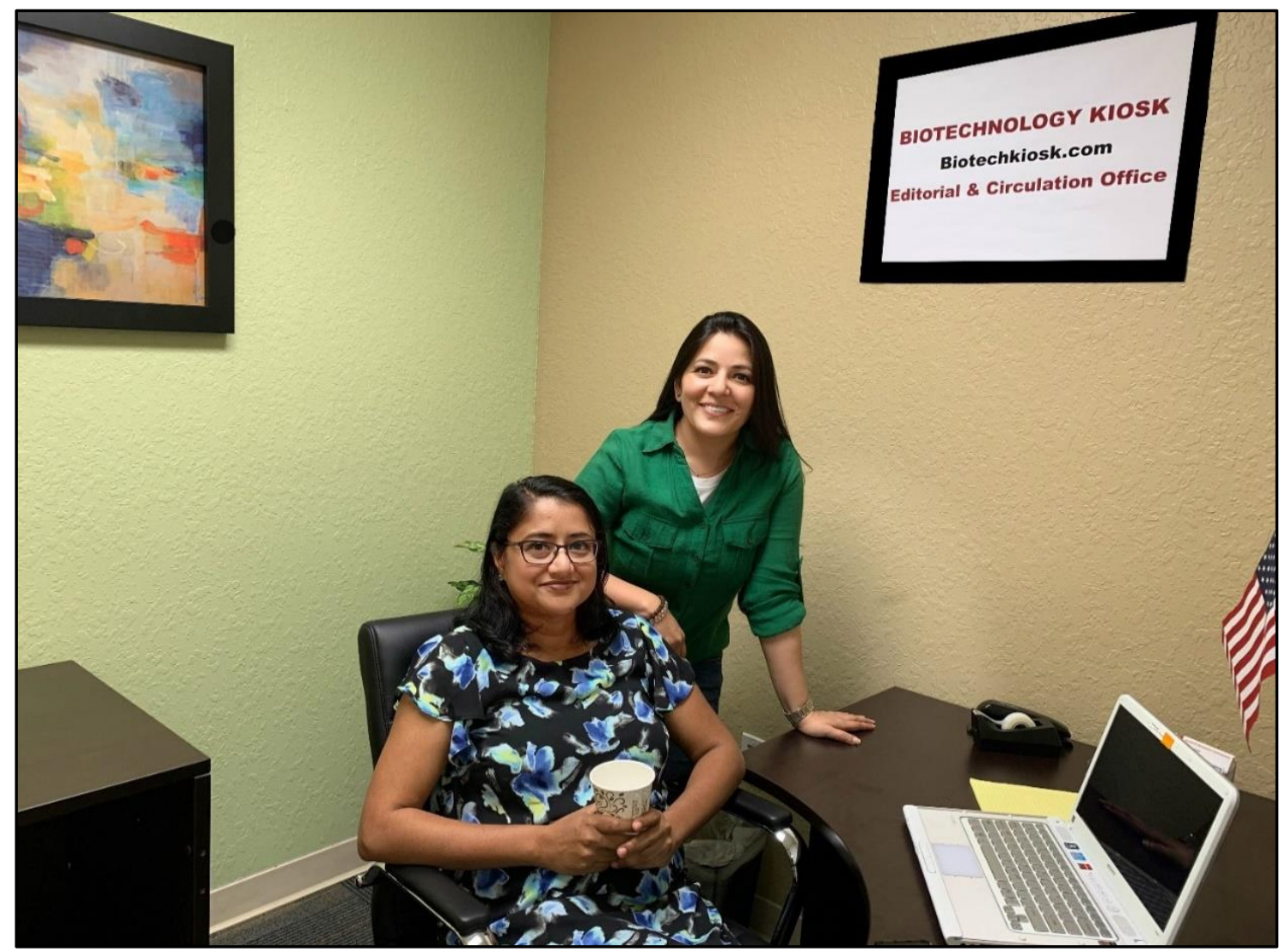

\section{Welcome to Biotechnology Kiosk!}

This is another issue presented to our readers with the regular features that include high-end editorials by experts, biotechnology advances around the world and industry news from pharma and biotech sectors.

This issue contains articles in the field of COVID-19 and paranoia and mental health along with news and views on the current cutting edge topics that include latest research breakthroughs in Parkinson' Disease, malaria and advanced vaccines and several other topics that have been discussed in the editor's choice that reports on research breakthroughs from around the world.

We look forward to receiving your contributions. We do hope that you will enjoy reading this issue of Biotechnology Kiosk. Please do write to us with your comments and feedback. Your suggestions are always appreciated.

Dr. Megha Agrawal and Dr. Shyamasri Biswas

Co Editors-in-Chief, Biotechnology Kios 


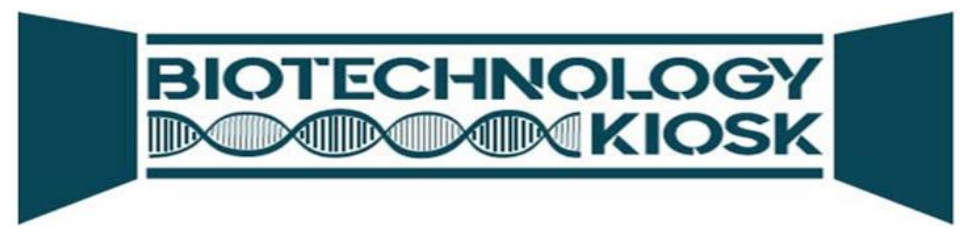

\section{Contents}

Volume 2, Issue 6

June 2020

COLUMNS

COVID-19 AND BRAIN HEALTH

4

Global pandemic takes a toll on our brain health: how unexpected uncertainty makes you vulnerable to paranoia

https://doi.org/10.37756/bk.20.2.6.1

COVID-19 AND ANTIBODIES

Neutralizing antibodies: Viable treatment modality for COVID-19

https://doi.org/10.37756/bk.20.2.6.2

BIOTECH R\&D AND INNOVATION NEWS.

Editor's PICKS: Biotechnology Advances around the World

Malaria and Vaccines .18

Parkinson' Disease

Agriculture and Food Science .20

COVID-19 and Blood Clots .21

BIOTECH AND PHARMA INDUSTRY ROUNDUP

COVID-19 vaccine by Pfizer and BioNTech's shows positive data .22

A $\$ 900$ million collaboration between Takeda and Carmine. .22

A New H1N1 Strain can trigger another global pandemic .22 FDA approves Pfizer and Merck KGaA's Bavencio 22 




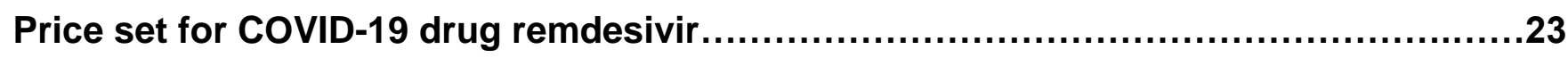



Novartis partners with Eye \& Ear hospital to manufacture coronavirus vaccine ............24

WHO plan to deliver 2 billion coronavirus vaccine doses....................................24

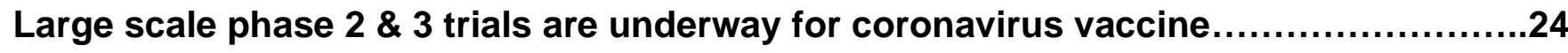

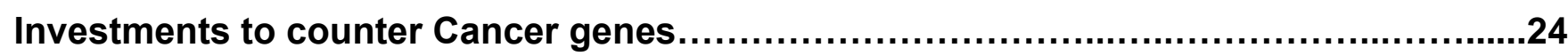

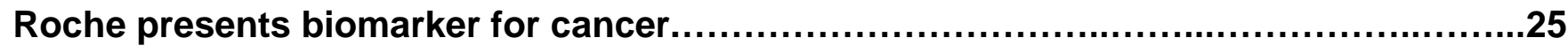

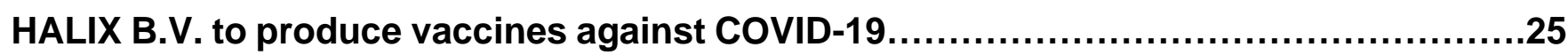

SARS-CoV2 antibody tests might not be suitable for individual diagnosis.................25

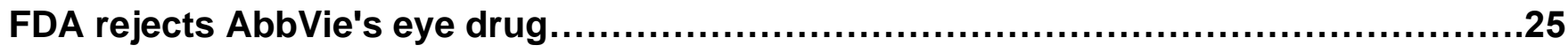

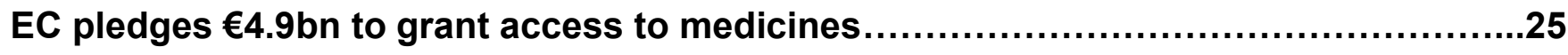

No beneficial effect of lopinavir-ritonavir on COVID-19 patients ...........................25 


\title{
COLUMN
}

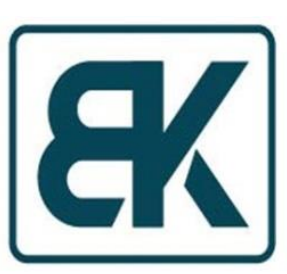

\section{COVID-19 and Brain Health}

\author{
By Shripriya Singh, PhD \\ Contributing Editor \\ Biotechnology Kiosk, 2, 6 (2020) \\ DOI: https://doi.org/10.37756/bk.20.2.6.1
}

\section{Global pandemic takes a toll on our brain health: how unexpected uncertainty makes you vulnerable to paranoia}

\begin{abstract}
Human beings are susceptible to their changing social environments and these changes take a toll on our brain health. In a state of crisis such as the global pandemic Covid-19 we have experienced random unexpected uncertainty which can lead to induced paranoia in healthy individuals. Paranoia is a key symptom of serious mental illness, characterized by the belief that other people have malicious intentions and that harm will occur due to the deliberate actions of others. Although it also exists in normal populations but gets triggered more in cases of stress, social threats, drug abuse and personality disorders. Here we discuss a study which employed computational modeling and reversal learning behavior to estimate belief updating across online participants, individuals with and without mental illness and rats chronically exposed to methamphetamine, an elicitor of paranoia in humans. This study is an attempt to unravel the underlying mechanism of paranoia and give possible cues towards the development of new treatments. If paranoia can be induced in model organisms without taking the social interaction into consideration it will simplify the research intricacies and will open new possibilities of a potential cure.
\end{abstract}

Keywords: Paranoia; brain health; methamphetamine; reversal learning behavior; Covid-19

\section{*E-Mail: shripriyasingh@gmail.com}

To cite this article: Singh S; Global pandemic takes a toll on our brain health: how unexpected uncertainty makes you vulnerable to paranoia, Biotechnology Kiosk, Vol 2, Issue 6, PP: 4-9 (2020); DOI:

https://doi.org/10.37756/bk.20.2.6.1 


\section{Paranoia: A key symptom of serious mental illness}

It is popularly said the biggest fear is 'the fear of the unknown' and rightly so because what we have not encountered is what we cannot defeat. It is absolutely normal for any human being to harbor fear, anxieties and apprehensions regarding various aspects of life, however, the difficulty arise when we are unable to overcome these dominant negative mental traits. Especially during these difficult times of global pandemic caused by COVID19 , mental health is a matter of current interest and has become a hot-spot issue with everyone around suddenly becoming aware of it. To briefly explain mental health comprises our psychological, emotional, and social well-being. It affects our thoughts, feelings as well as actions. In recent times we see this mental health issue being acknowledged at various social media portals and confessions by celebrities will always add the extra zing to it. However, for anyone who takes interest in the topic will have to turn towards core neuroscience for answers.

All living organisms are constantly evolving and adapting to their changing environments and each one of us has been programmed biologically to respond to these changes. Our survival instincts are strong enough to enable us to fight and face any drastic change in our surroundings. However, for human beings it's not just about survival but also about maintaining sanity and sustaining brain health.

We have highlighted and addressed the importance of brain health and mental wellbeing in two of our previous articles namely "The tussle between the developing adolescent brain and dietary choices: who's the target who's the trigger?" and "Worries make you look older: unraveling the science that connects stress with graying in human beings." Delving further in the issue we chose 'paranoia' as our current topic for discussion.

Paranoia is a key symptom of serious mental illness, characterized by the belief that other people have malicious intentions and that harm will occur due to the deliberate actions of others (1). For a layman paranoia can be explained as a thought process that makes you irrationally suspicious and mistrust others. Paranoid individuals feel that someone is out to get them or they're being persecuted. They fear the threat of physical harm even if there is no possible danger. It is a prevalent trait in dementia patients, drug addicts and people with personality disorders. However, paranoid behavior is also observed in perfectly healthy individuals under conditions of stress, competition, drastic changes and so on. A team of researchers from Yale University have provided scientific evidence in favor of a theory that unexpected uncertainty can breed paranoia. Their study highlights the fact that in times of unexpected uncertainty such as a global pandemic like COVID-19 people are likely to get prone to paranoia. In this article we shall briefly describe and discuss this interesting piece of literature published in the journal eLife (2).

\section{What the study unravels?}

According to Yale's Philip Corlett, associate professor of psychiatry and senior author of the study, "When our world changes 
unexpectedly, we want to blame that volatility on somebody, to make sense of it, and perhaps neutralize it,". The year 2020 has been wreaking havoc globally in the form of the Covid-19 pandemic. This is a changing global scenario where we as a human race stand together against fighting this catastrophe. In times of unexpected uncertainty our abilities to cope with a crisis are challenged and this leads to mental health problems like paranoia. Figure 1 summarizes the brain areas associated with different brain disorders.

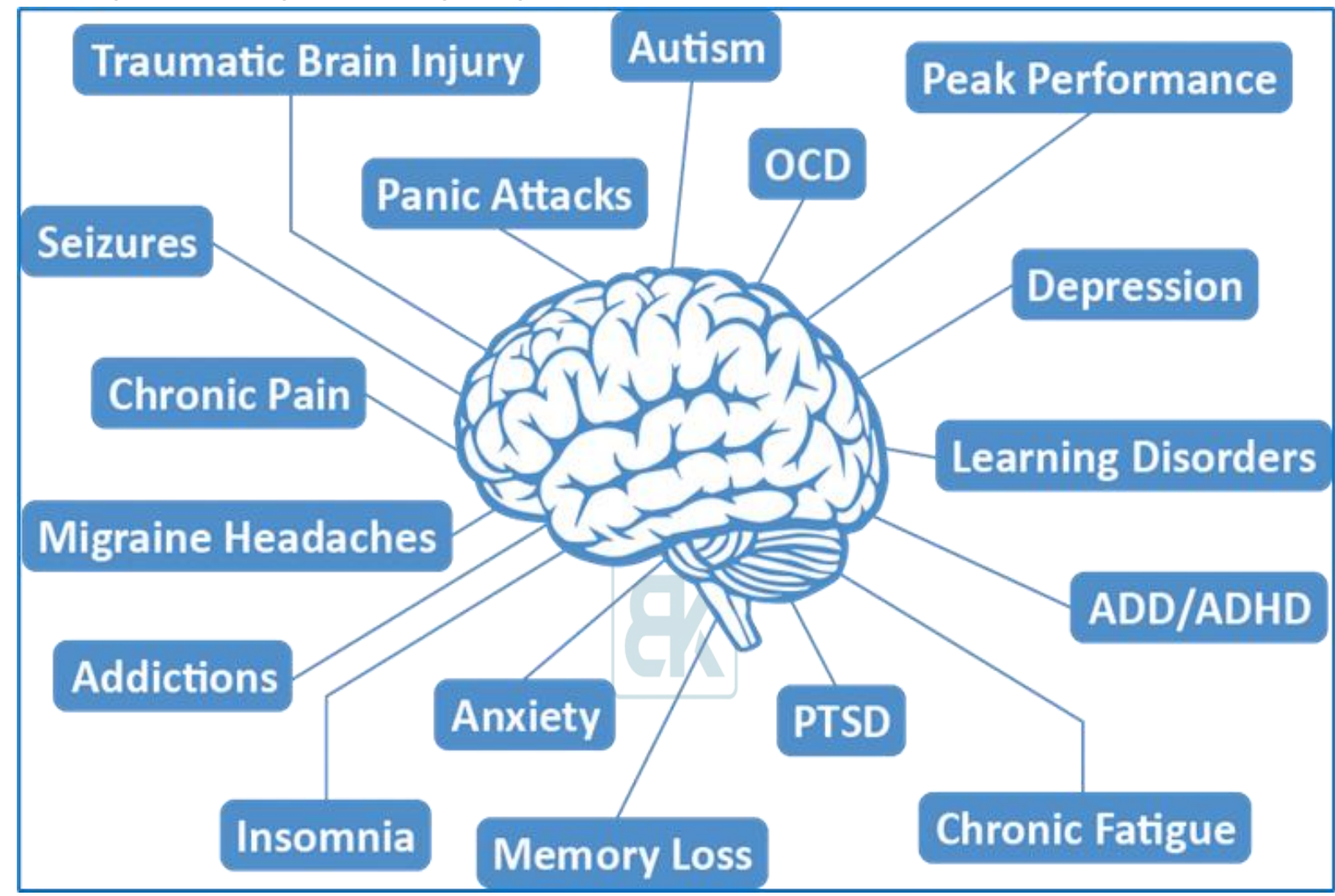

Figure 1: Diagrammatic brain map to show the different areas of the brain responsible for the different brain disorders [Source: https://www.pngwing.com/en/free-png-pbnom].

It is theorized that paranoia arises due to an inability to accurately assess social threats. However, lead author of the study Erin Reed and Philip Corlett hypothesized that paranoia is instead rooted in a more basic learning mechanism that is triggered by uncertainty, even in the absence of social threat. According to Reed, "We think of the brain as a prediction machine; unexpected change, whether social or not, may constitute a type of threat -- it limits the brain's ability to make predictions". "Paranoia may be a response to uncertainty in general, and social interactions can be particularly complex and difficult to predict."

The current study employs the use of reversal learning behavior and computational modeling to estimate belief updating across individuals with and without mental illness and online participants. To briefly explain the study, a series of experiments were carried out where human subjects with different degrees of paranoia were made to play a 
card game in which the best choices for success were secretly changed. Individuals with little or no paranoia were slow to assume that the best choice had changed. But paranoid individuals expected even more volatility and unpredictability in the game. Despite winning they changed their choices impulsively and in a more erratic manner. The researchers then amplified the levels of uncertainty by changing the chances of winning halfway through the game without informing the participants. This sudden unexpected change in the situation made even the low-paranoia participants behave like those with paranoia, learning less from the consequences of their choices.
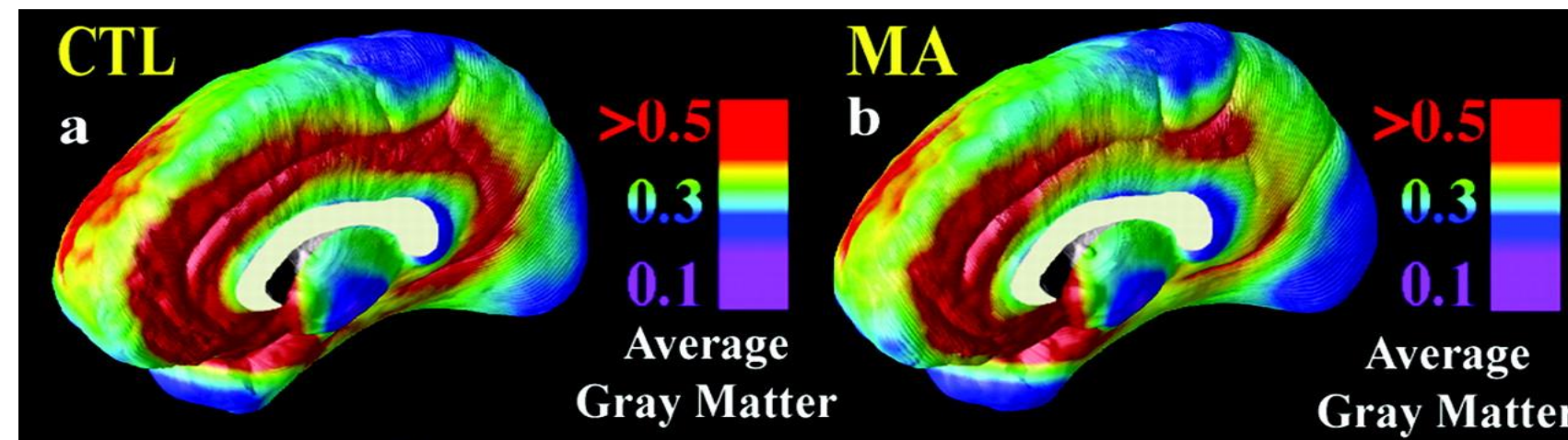

Gray Matter
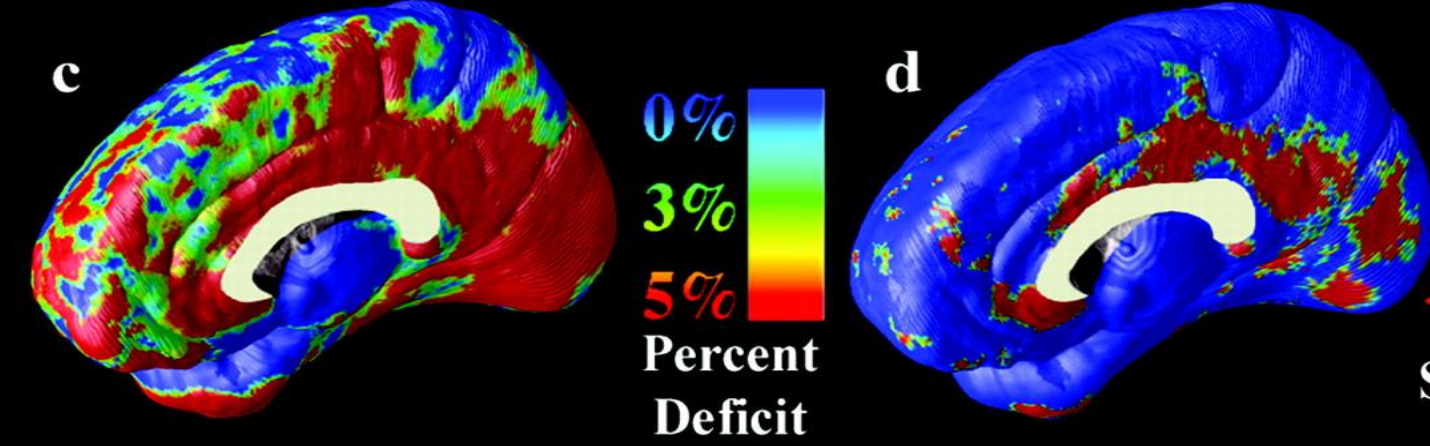

Average Gray Matter

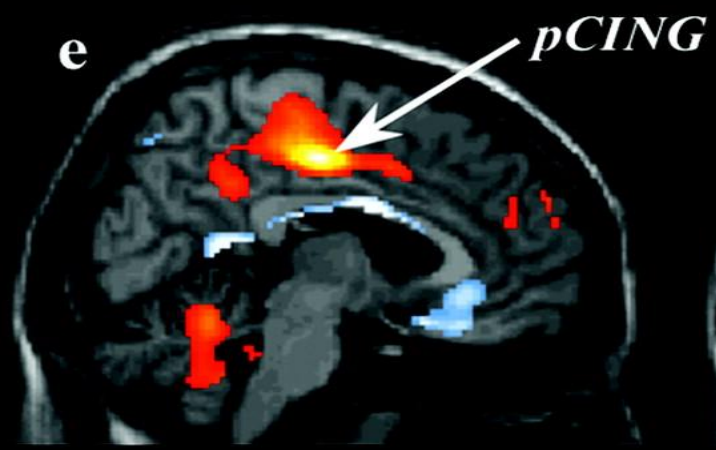

R hem.

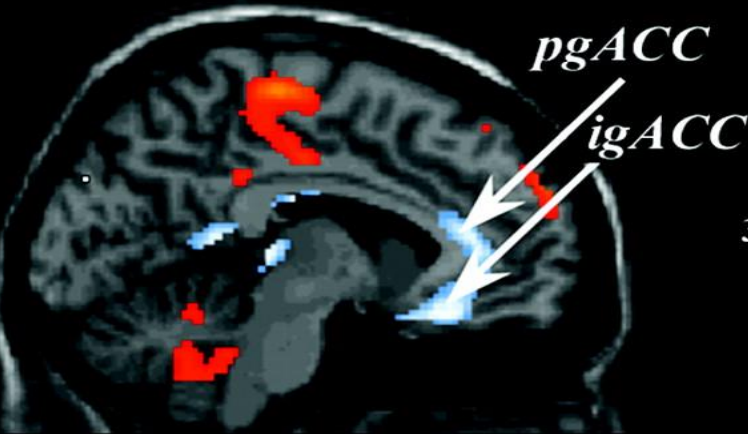

L hem.



Figure 2: Neuroimaging data of brain of healthy human versus methamphetamine user showing gray-matter differences on the medial brain surfaces. Group difference maps (c) show mean percentage differences in gray-matter volumes between the control group average (a) and the methamphetamine group average (b), according to the color bar. The significance of these reductions is plotted in d as a map of $p$ values [Source: Journal of Neuroscience,2004(5)]. 


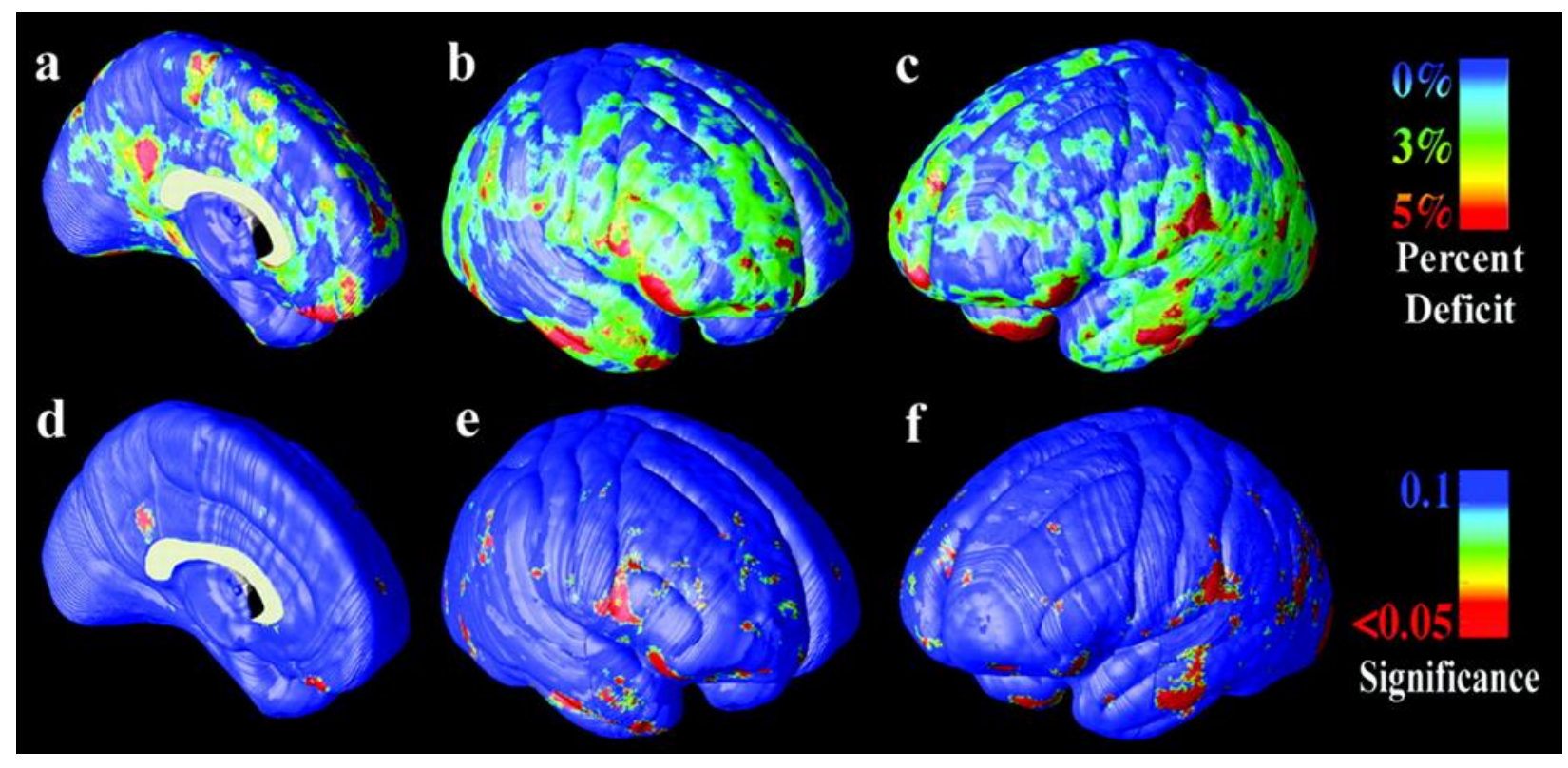

Figure 3: Neuroimaging data of brain of healthy human versus methamphetamine user showing gray-matter differences on the lateral brain surfaces. The mean reduction in gray matter in the MA group, relative to healthy controls, is expressed as a percentage and shown color-coded (red colors-greater reduction; blue colors- no reduction;) [Source: Journal of Neuroscience ,2004 (5)].

In order to check for translation in other species rodent data was also taken into consideration. Yale collaborators Jane Taylor and Stephanie Groman carried out a similar experiment in rats where they trained them to perform a task where best choices of success were changed (3). Rats were chronically exposed to methamphetamine, an elicitor of paranoia in humans. Methamphetamine exposure in rats recapitulates the impaired uncertainty-driven belief updating and rigid anticipation of a volatile environment (2). Therefore, these rats then behaved like paranoid humans and anticipated high volatility and relied more on their expectations than learning from the task. Reed, Corlett and their team then used computational modeling approach and employed hierarchical Gaussian filter (HGF) modeling (4) to compare choices made by humans and rats while performing these similar tasks. The researchers found that the results from the rats that received methamphetamine resembled those of humans with paranoia. The complexity of the human brain gives rise to a number of brain disorders and anomalies which are sometimes beyond treatment and cure. However, if we can narrow down on the molecular targets and signaling aspects it becomes feasible to design therapy and drugs. This study is an attempt to unravel the underlying mechanism of paranoia and give possible cues towards the development of new treatments. If paranoia can be induced in model organisms without taking the social interaction into consideration it will simplify the research endeavor and will open new possibilities of a potential cure. Figures 2 and 3 show the neuroimaging data of structural 
abnormalities in the brains of human subjects who use methamphetamine in comparison to healthy controls (5).

\section{Concluding Remarks}

Neurodegenerative diseases and mental health disorders are largely incurable and pose not only a personal health threat but also a social health threat. When a person suffers from a brain disorder or a personality disorder he/she does not suffer alone, instead the entire family suffers. These mental health disorders can go largely unnoticed as people and families often shy away from even acknowledging the root cause of the problem. Therefore, along with medical and scientific research it is equally important that people are sensitized towards these aspects of brain health and encouraged to have a dialogue. Timely diagnosis of a brain disorder is crucial so that it can be managed if not cured. During this time of global crises several nations were under a complete lockdown state. This kind of a sudden uncertainty not only took a toll on our professional and social lives but also affected our brain health. Different people will perceive these changes in different manners; however, getting paranoid in such situations is a common feature. Thus it is important to understand how paranoia can be targeted and treated so that we have better therapeutics to handle brain health during times of global pandemics. The current piece of research has shed light on the various aspects of paranoia in humans as well as the asocial animal species such as rats. Hopefully in near future we shall have better treatments and therapeutics to cure mental health disorders such as paranoia so that at least we can ensure a population of sane and mentally healthy individuals who can cope with the side effects pandemics like Covid19.

\section{References}

1. Freeman D \& Garety PA (2000) Comments on the content of persecutory delusions: does the definition need clarification? British Journal of Clinical Psychology 39(4):407-414.

DOI: $\underline{10.1348 / 014466500163400}$

2. Reed EJ, et al. (2020) Paranoia as a deficit in non-social belief updating. Elife 9:e56345. DOI: $\underline{10.7554 / e L i f e .56345}$

3. Groman SM, Rich KM, Smith NJ, Lee D, \& Taylor JR (2018) Chronic exposure to methamphetamine disrupts reinforcement-based decision making in rats. Neuropsychopharmacology 43(4):770-780.

DOI:10.1038/npp.2017.159

4. Mathys CD, et al. (2014) Uncertainty in perception and the Hierarchical Gaussian Filter. Frontiers in human neuroscience 8:825. DOI: $10.3389 /$ fnhum.2014.00825

5. Thompson PM, et al. (2004) Structural abnormalities in the brains of human subjects who use methamphetamine. Journal of Neuroscience 24(26):60286036. DOI: $10.1523 /$ JNEUROSCI.0713$\underline{04.2004}$ 


\title{
REVIEW ARTICLE
}

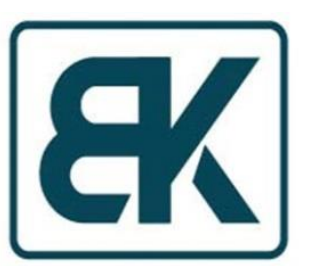

\section{COVID-19 and Antibodies}

Sangeeta Chakraborty, PhD

National Jewish Health, Denver, Colorado, USA

Biotechnology Kiosk, 2, 6 (2020)

DOI: https://doi.org/10.37756/bk.20.2.6.2

\section{Neutralizing antibodies: Viable treatment modality for COVID-19}

\begin{abstract}
SARS-CoV-2, the highly transmissible and infectious novel coronavirus, is responsible for the current COVID-19 pandemic. Therapeutic efforts toward the development of a vaccine and other treatment modalities are a priority. High-affinity neutralizing antibodies play a critical role in protection against viruses so a rapid development to identify such neutralizers against SARSCoV-2 that also cross-protect against other coronaviruses is warranted. Here, we review current research on the isolation of SARS-CoV-2 neutralizing monoclonal antibodies from B cells of convalescent patients and their effectiveness in a small animal model to limit the viral disease. The antibodies that were able to successfully treat COVID-19 in the animals were highly specific against the ACE2 binding site of the viral spike protein and thus efficiently blocked infection.
\end{abstract}

Keywords: SARS-CoV-2, COVID-19, nAbs, ACE2, Spike protein, monoclonal antibody, antibody therapy

*E-Mail: sangeeta1986@gmail.com

To cite this article: Chakraborty S; Neutralizing antibodies: Viable treatment modality for COVID-19, Biotechnology Kiosk, Vol 2, Issue 6, PP: 10-16 (2020); DOI: https://doi.org/10.37756/bk.20.2.6.1 


\section{Introduction}

COVID-19 (coronavirus disease 2019), caused by SARS-CoV-2 has created quite a mayhem in the public health domain within a short span of time. With more than 400,000 deaths worldwide as of 19 th June 2020 , the race is on to create a vaccine against the virus. In the interim, other therapeutic efforts to prevent or limit the disease have also gained momentum. Researchers are focusing on old antiviral drugs and antibodybased therapies to curb the spread of SARSCoV-2.

Repurposed old drugs like remdesivir-a broad spectrum antiviral, baricitinib-an oral JAK1/JAK2 inhibitor and dexamethasone-a glucocorticoid have shown promising results in late-stage clinical trials while Ly-CoV555-a neutralizing monoclonal antibody against SARS-CoV-2 spike (S) protein has already entered phase I trials as the world's first potential COVID-19 antibody treatment. One of the critical advantages of neutralizing antibodies is their specificity toward the viral target that selectively and directly blocks infection. But beyond just blunting the viral propagation, these antibodies have the potential to generate vaccine-like effects also by inducing or modulating the endogenous antiviral immune responses (eliciting both humoral and cellular responses) [1]. Unlike cancer and inflammatory disease, where antibodies constitute a large proportion of treatment modalities, their use against viral infections has not gained much popularity until recently in the COVID-19 era.

In light of the lack of effective therapies for COVID-19, usage of convalescent plasma with high neutralizing titers has been shown to provide some clinical benefits to hospitalized patients. Given the limitations associated with such therapies, including variability in titers, contamination risks, and circulatory overload, numerous researchers have focused on employing monoclonal antibodies instead [2].

\section{Antibody Therapy against viruses}

Monoclonal antibodies (mAbs) have shown enormous potential in the last two decades as a significant therapeutic modality against infectious diseases, especially with Ebola and HIV [3]. Antiviral mAbs can limit viral propagation in a number of ways a) by physically blocking the site of virus interaction with host cell-also known as neutralization b) by coating the virus in an immune complex to make it susceptible to digestion by serum complement or professional phagocytes, and c) by facilitating endocytosis of antibody bound virions into professional antigenpresenting cells (APCs) leading to an antiviral cellular immune response [4].

Enveloped viruses like SARS-CoV-2 usually elicit strong antibody responses against their envelope spike proteins that lay exposed on the surface [1]. The repertoire of such antibodies against spike proteins may reduce viral burden through several mechanisms, but only a subset of those can neutralize the infectivity of the virus to host cells. In other words, not all elicited antibodies that bind to the spike protein can neutralize the virus [5]. Therefore, for therapeutic use, isolation of neutralizing monoclonal antibodies (nAbs) that can bind (with high affinity) to the host cell interacting sites of the spike protein and block the 
biological activity/infectivity of the virus, is highly desirable. Monoclonal nAbs are isolated from single-memory or plasma $B$ cells retrieved from vaccinated or naturally infected animals and human donors. A nAb against the respiratory syncytial virus (RSV) is in clinical use to prophylactically prevent infections in infants [6].

\section{The case of SARS-CoV-2}

Coronaviruses are enveloped viruses, and as described above, the viral surface spike (S) protein presents a predominant target for nAbs. SARS-CoV-2 $S$ protein-a trimeric type I membrane glycoprotein-mediates viral attachment and entry into host cells through binding to the ACE2 receptor. The approximately $200 \mathrm{kDa} S$ protein has two functional subunits-S1 (further divided into four core domains S1A through S1D) and S2, based on a host protease cleave site. The receptor-binding domain $(\mathrm{RBD})$ resides in the $\mathrm{N}$-terminal $\mathrm{S} 1$ subunit, while membraneanchored S2 facilitates the fusion of the viral membrane with cellular membrane. Neutralizing antibodies against the RBD that can disable receptor interactions are often the most potent neutralizers, desired for their therapeutic potential [7][Figure 1].

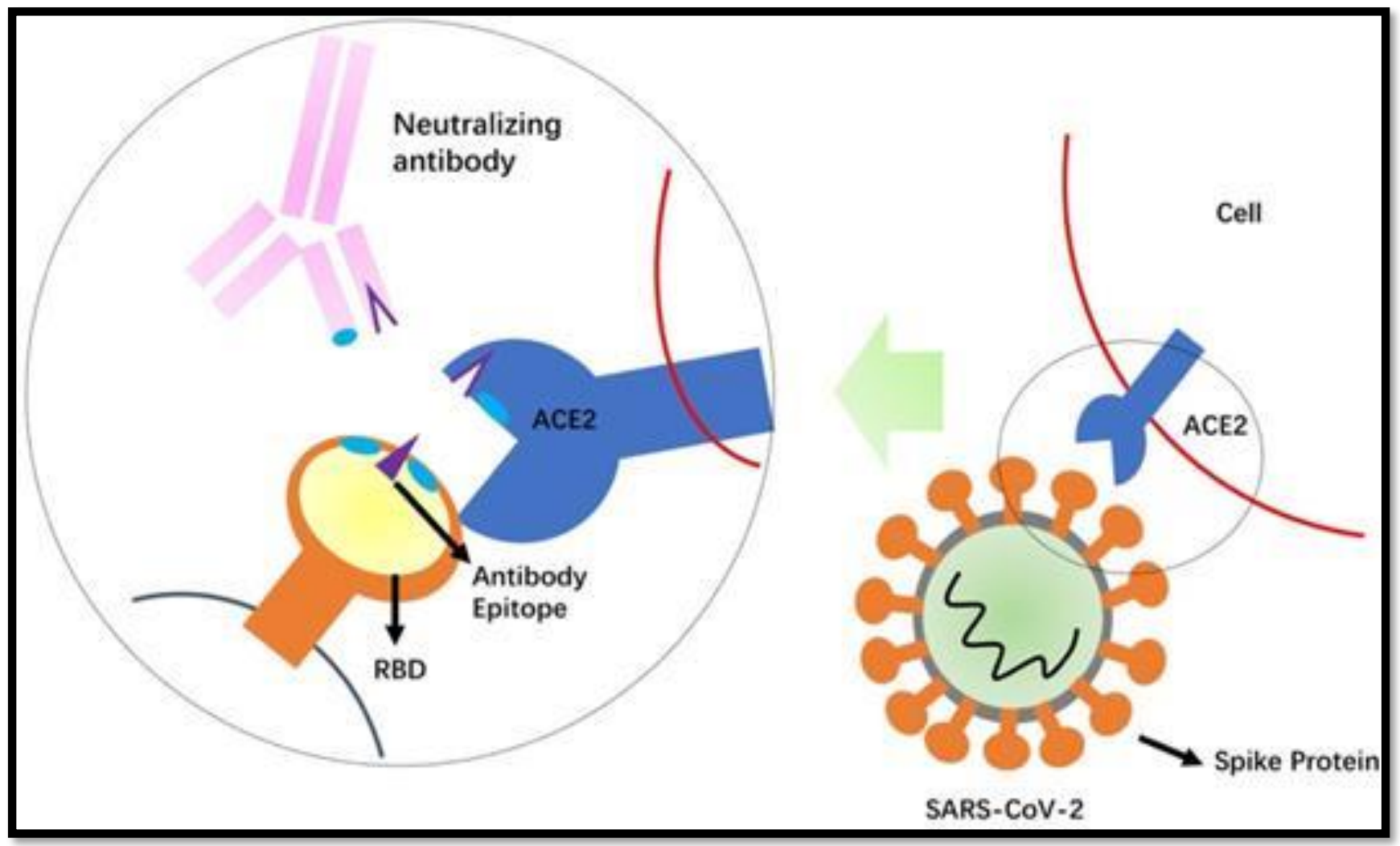

Figure 1: Schematic mechanism of the neutralizing antibodies. Competition of the neutralizing antibody with the receptor (ACE2) for binding to the receptor-binding domain (RBD) of the SARSCoV-2 Spike protein is shown. The protruding portion (violet) of RBD is both the ACE2 receptorbinding site and the antibody epitope. [Source: Int J Biol Sci (2020)]. 


\section{The current state of SARS-CoV-2 nAbs}

Polyclonal antibodies isolated from COVID19 recovered patients are currently in use to treat sick COVID-19 cases in the absence of any specific anti-SARS-CoV-2 monoclonal neutralizing antibody. However, many efforts have been going on toward isolating neutralizing mAbs that can be used either prophylactically or therapeutically postexposure to prevent or treat COVID-19, respectively. Once isolated, the shortlisted $\mathrm{nAb}$ candidates will undergo rigorous in vitro testing for neutralizing and/or crossneutralizing activity, efficacy assessment in COVID-19 animal models followed by preclinical and clinical trials before they are ready for human use [8].

Some of the notable SARS-CoV-2 nAbs that have been recently developed are:

1. 47D11-first report of a human monoclonal antibody that crossneutralizes both SARS-CoV-2 and SARS-CoV by binding a conserved epitope on the spike RBD [9]

2. S309-neutralizes SARS-CoV-2 by engaging the $S$ receptor-binding domain [10]

3. B38 and H4-neutralizes SARS-CoV-2 by blocking the RBD of the viral spike protein from binding to the ACE2 receptor [11]

\section{SARS-CoV-2 nAbs -from discovery to animal testing}

Another recent research that adds to the current list of SARS-CoV-2 specific monoclonal antibodies came from Scripps
Research Institute in collaboration with UC San Diego. Rogers et.al employed a deep mining approach coupled with highthroughput screening to isolate high-potency neutralizing antibodies against SARS-CoV-2 from the blood of recovered COVID-19 patients [6].[Figure 2]

They began by isolating SARS-CoV-2 specific memory $B$ cells from donor plasma by capturing them with RBD and $S$ antigen baits. The pool of SARS-CoV2 specific B cells expressing either anti-S or anti-RBD antibodies were flow-cytometrically sorted, and their heavy $(H)$ and light $(L)$ chain genes were PCR-amplified and cloned into expression vectors.

Transfection of the cloned $\mathrm{H}+\mathrm{L}$ chain pairs into high-efficiency expression cell line yielded monoclonal lgGs in the supernatant. The secreted IgGs were tested for their efficacy to neutralize both live and pseudo SARS-CoV-2. [Pseudo SARS-CoV-2 (PSV)—a replication-deficient MLV (Murine Leukemia virus)-Luciferase vector possessing a truncated version of SARSCoV-2 envelop protein (a truncation of $S$ protein- $\Delta 18 \mathrm{~S}$ allows pseudo virion maturation at the cell membrane because it removes the ER retention signal)]

In a virus neutralization assay, the authors first mixed the live SARS-CoV-2 or the pseudoSARS-CoV-2 with the IgG monoclonal antibodies. This premixing allowed the antibodies to bind to their corresponding antigenic sites, in this case, sites on $S$ protein and the RBD of the virus. The virus/mAb premix was then applied to a monolayer of HeLa-ACE2 (target cells), to determine infection based on either plaque 
formation or luminescence (depending on whether the virus was live or pseudoyped). In this case, any antibody that blocks the viral interaction with ACE2 would not result in a plaque or luminescence, making it a neutralizing antibody as opposed to any other monoclonal antibody that binds to the $S$ protein but does not block infection (also known as binding antibody).

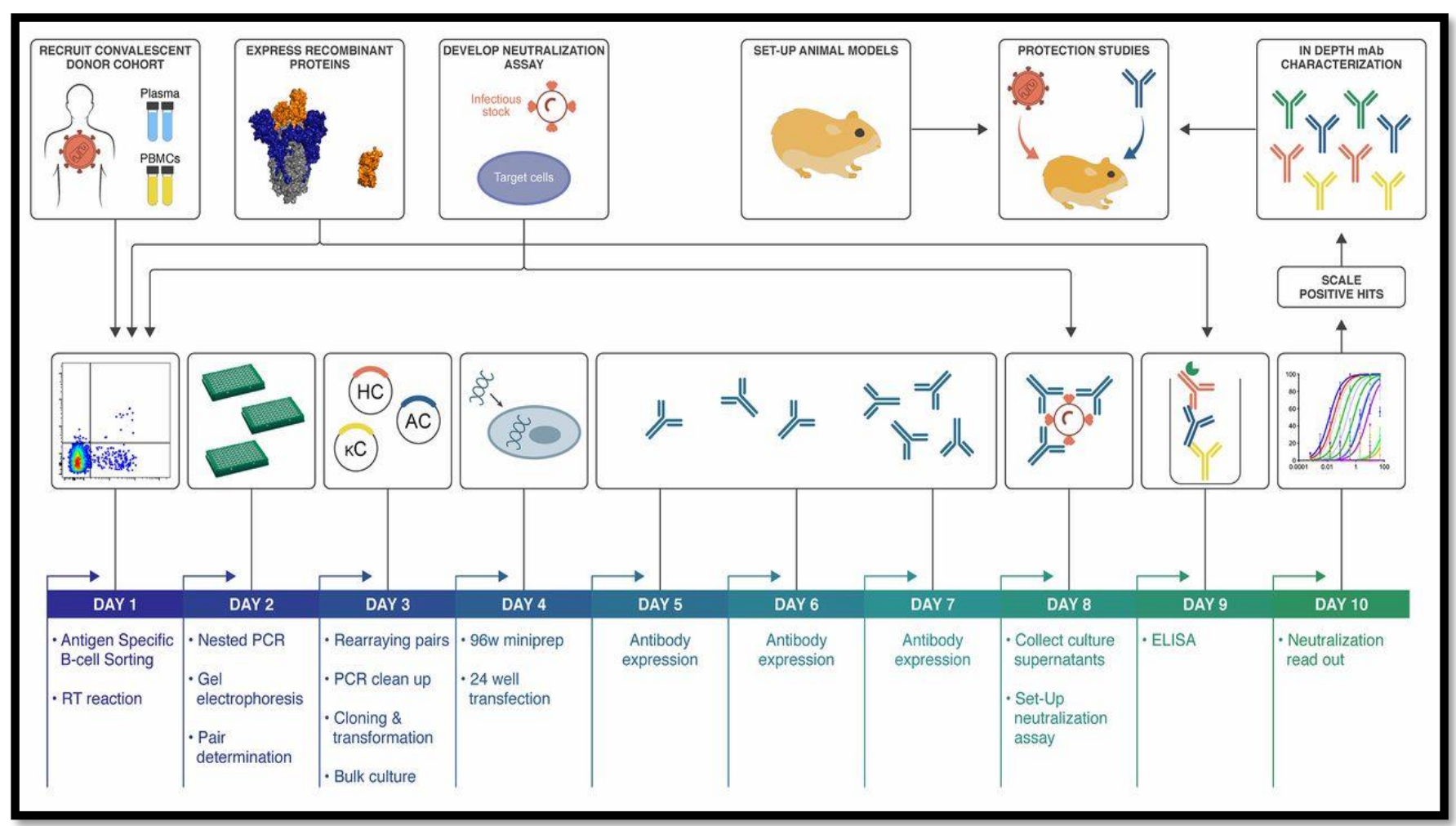

Figure 2: A natural infection cohort was established to collect plasma and PBMC samples from individuals who recovered from COVID-19. In parallel, functional assays were developed to rapidly screen plasma samples for SARS-CoV-2 neutralizing activity. SARS-CoV-2 recombinant surface proteins were also produced to use as baits in single memory $B$ cell sorting and downstream functional characterization of isolated mAbs. Finally, a Syrian hamster animal model was set-up to evaluate $m A b$ passive immunization and protection. The standard mAb isolation pipeline was optimized to facilitate high-throughput amplification, cloning, expression and functional screening of hundreds of unpurified $A b$ heavy and light chain pairs isolated from each of several selected neutralizers in only 10 days. Selected pairs were scaled-up to purify IgG for validation and characterization experiments. Potent neutralizing $m A$ Abs were selected to evaluate protection in the Syrian hamster model. [Source: Science (2020)].

As mentioned previously, not all viral protein binding antibodies are capable of neutralizing the virus, thus going by the same logic, the authors found that most of the potent neutralizers were RBD+ binders. Despite S+ binders comprising a large proportion of all anti-SARS-CoV-2 antibodies, they were not neutralizing types. 
Next, the panel of potent neutralizers was characterized for their epitope specificities. The authors attached a biosensing platform with $S$ and RBD antigens. They inundated the bound antigen surface with saturating concentrations of the neutralizing antibodies (found in the previous step) along with lower levels of other competing antibodies (4:1 ratio). This approach enriched only those nAbs that bound to non-competing sites. Predominant epitopes on RBD and $S$ proteins were subdivided into-RBD-A, RBD-B, RBD-C and $S-A, S-B$, and $S-C$ respectively.

Anti-RBD-A nAbs turned out to be the most potent neutralizers with IC50 values approaching single digits followed by an antiRBD-B antibody while all non-RBD, but anti$S$ antibodies showed poor neutralization abilities. Since the extent of neutralization depends on the precise placement of the antibody at the interaction site of viral spike protein and host receptor, anti-RBD antibodies turned out to be the best candidates.

Two antibodies-anti-RBD-A nAb and an anti-S-B nAb were selected to evaluate their in vivo efficacy against SARS-CoV-2 in a Syrian hamster model. The anti-RBD-A $n A b$ had an in vitro IC50 neutralization of $0.019 \mu \mathrm{g} / \mathrm{ml}$ against the pseudovirus, whereas anti-S-B nAb had IC50 neutralization of $22 \mu \mathrm{g} / \mathrm{ml}$. Hamsters generally clear SARS-CoV-1 infection in one week so SARS-CoV-2 infection was followed for a week with weight loss and elevated lung viral titers as signs of infection. In a dose dependent manner, the antibody against RBD-A was able to reduce the disease burden while anti-S-B nAb failed to do so at any dose.

\section{Conclusion and Outlook}

Antibody-based therapy has come a long way from the administration of immune serum to passive infusion of highly selective human monoclonal antibodies. In the absence of any vaccine, monoclonal antibodies could be an alternative avenue to limit the impact of COVID-19. But this treatment modality is not without its fair share of pitfalls. Neutralizing antibodies in convalescent patients do not reach high titers, as exemplified by some recent studies, and moreover, the levels quickly subside following recovery. In this setting, the pipeline for the development of potent neutralizers derived from strong viral epitopes that can provide long-lasting immunity is both complicated and tedious given the time required for validation and screening of those antibodies for potency (in both animal models and clinical trials), and high costs of production before clinical use. Competition with other forms of treatment like small molecule antivirals, which are much more cost-effective to produce and distribute, further limits the scope of antibody treatments for viral diseases [2].

Nevertheless,

passive immunotherapy with nAbs is quick and in the context of COVID-19, they can confer immediate protection to populations that are highly vulnerable to infection and places where outbreaks are rampant including nursing homes and meat-packing facilities. Additionally, passive infusion of nAbs in elderly individuals could provide rapid protection considering vaccine-elicited 
immune responses take time to mount in these individuals [2].

Neutralizing monoclonal antibodies to SARS-CoV-2 not only have the potential as prophylactic and therapeutic agents, but they can also inform new vaccine design through the identification of usable epitopes. Furthermore, broad cross-reactive nAbs that are capable of neutralizing other coronaviruses too can be the weapon to fight the current pandemic as well as any future outbreaks that humans might face.

\section{References:}

1. Pelegrin $M$, Naranjo-Gomez $M$, Piechaczyk M. Antiviral Monoclonal Antibodies: Can They Be More Than Simple Neutralizing Agents? Trends Microbiol. 2015;23(10):653-665.

DOI: 10.1016/j.tim.2015.07.005

2. Marovich M, Mascola JR, Cohen MS. Monoclonal Antibodies for Prevention and Treatment of COVID-19 [published online ahead of print, 2020 Jun 15]. JAMA. DOI: 10.1001/jama.2020.10245

3. Walker LM, Burton DR. Passive immunotherapy of viral infections: 'superantibodies' enter the fray. Nat Rev Immunol. 2018;18(5):297-308. DOI: 10.1038/nri.2017.148

4. Murin $C D$, Wilson IA, Ward AB. Antibody responses to viral infections: a structural perspective across three different enveloped viruses. Nat Microbiol. 2019;4(5):734-747. DOI: 10.1038/s41564019-0392-y

5. Burton DR, Williamson RA, Parren PW. Antibody and virus: binding and neutralization. Virology. 2000;270(1):1-3 DOI: 10.1006/viro.2000.0239

6. Rogers TF, Zhao F, Huang $D$, et al. Isolation of potent SARS-CoV-2 neutralizing antibodies and protection from disease in a small animal model [published online ahead of print, 2020 Jun 15]. Science. 2020;eabc7520. DOI: 10.1126/science.abc7520

7. Giroglou T, Cinatl J Jr, Rabenau H, et al. Retroviral vectors pseudotyped with severe acute respiratory syndrome coronavirus $\mathrm{S}$ protein. $\mathrm{J}$ Virol. 2004;78(17):9007-9015.

DOI:

10.1128/JVI.78.17.9007-9015.2004

8. Jiang S, Hillyer C, Du L. Neutralizing Antibodies against SARS-CoV-2 and Other Human Coronaviruses [published correction appears in Trends Immunol. 2020 Apr 24]. Trends Immunol. 2020;41(5):355-359.

DOI: $\underline{10.1016 / j . i t .2020 .03 .007}$

9. Wang C, Li W, Drabek D, et al. Publisher Correction: A human monoclonal antibody blocking SARS-CoV-2 infection. Nat Commun. 2020;11(1):2511. Published 2020 May 14. DOI: 10.1038/s41467-02016452-w

10. Pinto D, Park YJ, Beltramello $M$, et al. Cross-neutralization of SARS-CoV-2 by a human monoclonal SARS-CoV antibody [published online ahead of print, 2020 May 18]. Nature. 2020. DOI: 10.1038/s41586020-2349-y

11. Wu Y, Wang F, Shen C, et al. A noncompeting pair of human neutralizing antibodies block COVID-19 virus binding to its receptor ACE2. Science. 2020;368(6496):1274-1278.

DOI: $\underline{10.1126 / \text { science.abc2241 }}$ 


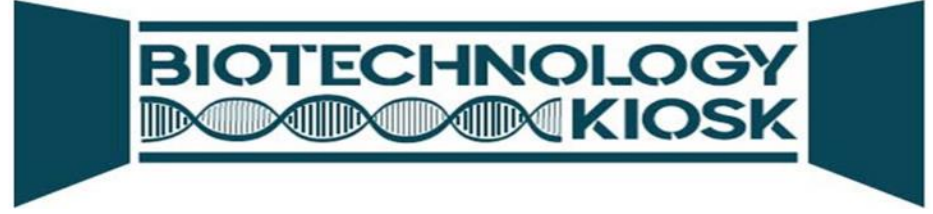 \\ Biotechnology Advances around the World Editor's Picks}

Every issue of Biotechnology Kiosk presents select latest research news picked by the editorsin-chief on significant research breakthroughs in different areas of biotechnology around the world. The aim is to promote further R\&D in all of these cutting edge areas of biotechnology. The editors have compiled and included the following innovations and breakthroughs to highlight the recent biotechnology advances.

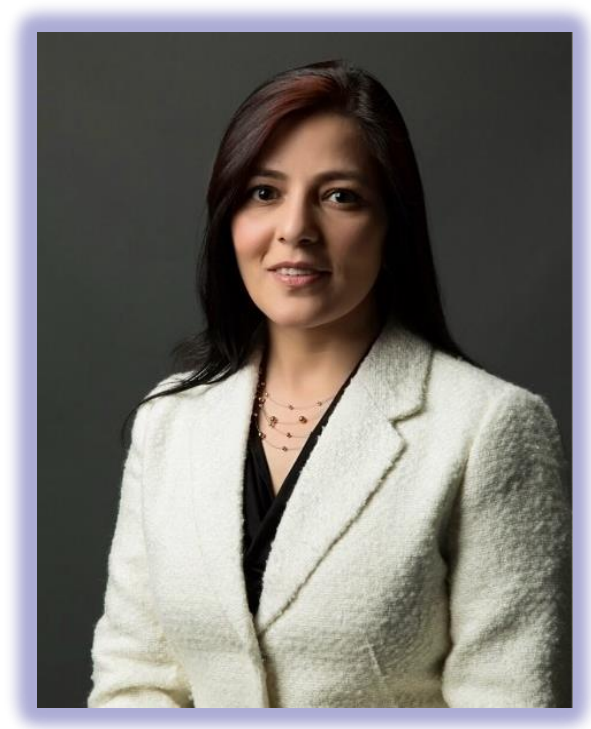

Dr. Megha Agrawal

Co Editor-in-Chief

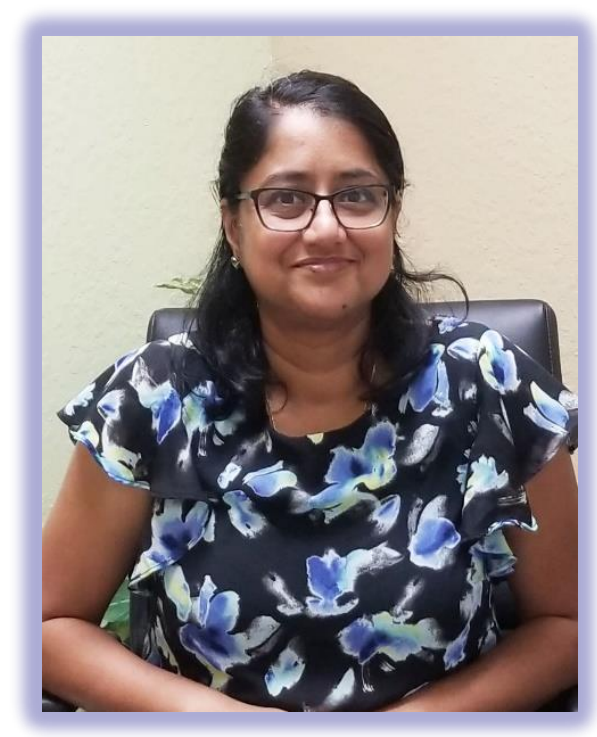
Dr. Shyamasri Biswas
Co Editor-in-Chief 


\section{Malaria and Vaccines}

Next generation vaccines against the deadliest form of malaria in humans

Malaria is considered a global threat to public health. As recently as 2018, 228 million new cases of malaria were reported globally with 405,000 fatalities. Children are considered the most vulnerable group with $61 \%$ of the reported deaths.

Successful eradication of malaria requires more effective vaccines against this deadly infectious disease that causes such a high mortality rate in the world. The existing most promising experimental vaccine candidates can only offer up to $52 \%$ protection in areas with intense malaria transmission. So, new and more advanced vaccines against malaria urgently need to be developed to combat the disease.

Especially, a vaccine is sought that targets the clinically silent phase of parasite infection in the liver and prevents blood stage infection. This would not only decrease mortality in especially vulnerable groups like children under the age 5 , but it would also block the cycle of transmission. This would lead to the ultimate malaria eradication. In a recent research of major significance, scientists in the United States have developed a genetically attenuated parasite (GAP) that arrests late in the liver stage of human malaria. Their findings were published in $\mathrm{JCl}$ Insight (A replicationcompetent late liver stage-attenuated human malaria parasite, JCl Insight, 2020; DOI: 10.1172/jci.insight.135589). This study paves the way for a novel, next generation vaccine against Plasmodium falciparum, the parasite that causes the deadliest form of malaria in humans.

Scientists engineered GAP by selecting genes that were deleted from the parasite's DNA. This approach allowed the GAPs to stop in the liver without ever reaching the dangerous blood stage of infection. They showed that the arrest of these GAPs in the liver resulted in exposing them to the immune system that engendered a powerful and effective immune response. This subsequently was demonstrated to block a new malaria infection from the moment a person received an infectious mosquito bite.

It was demonstrated that the deletion of Mei2 in both the rodent and human malaria strains caused the parasite to arrest very late in liver development. The research team then tested clones of $\mathrm{P}$. falciparum with the Mei2 GAP in human liver-chimeric mice. This model was used to study the human liver in the lab. Researchers found that these GAPs replicated as expected and arrested very late during liver stage development that did not transition to the blood stage.

Researchers envision that their new findings might pave the way for a novel, next generation genetically attenuated parasite (GAP) vaccine against the deadliest form of malaria in humans, which could help eradicate malaria in the world and save hundreds of thousands annually. 


\section{Parkinson' Disease}

New neurons and neurotransmitter dopamine to eliminate Parkinson' disease in a single treatment

It is known that loss of dopamine neurons in the substantia nigra is associated with Parkinson's disease (PD). Despite notable research advances made in $\mathrm{PD}$, there are no disease-modifying treatments available for this deadly disease. Existing treatment strategies target to prevent neuronal loss or protect vulnerable neuronal circuits. However, researchers have focused on a potential alternative, which is to replace lost neurons to reconstruct disrupted circuits. To this end, researchers around the world have tried many ways to generate neurons in the lab, using stem cells and other means with the aim to study them better and subsequently to use them to replace lost neurons in neurodegenerative diseases.

In this regard, recently researchers in the United States showed a very promising route of inhibiting a single gene to convert many cell types directly into dopamineproducing neurons. They discovered in a breakthrough research that a single treatment to inhibit a gene called PTB in mice can convert native astrocytes, star shaped brain support cells, into neurons. These neurons were shown to produce the neurotransmitter dopamine that eventually eliminated the mice's Parkinson's disease symptoms. Researchers recently reported the results of their study in Nature (Reversing a model of Parkinson's disease with in situ converted nigral neurons. Nature, 2020; 582 (7813): 550 DOI: 10.1038/s41586-020-2388$4)$.
In this study, researchers employed a protein called PTB. This protein is well known for binding RNA. It can also influence the genes to turn "on" or "off" in a cell. The role of this protein PTB has been studied by often manipulating cells to reduce the amount of the protein. By employing similar methodology, the research team discovered that inhibiting or deleting just a single gene encoding PTB can transform several types of mouse cells directly into neurons. In this approach, they administered the PTB antisense oligonucleotide treatment directly to the mouse's midbrain that was responsible for regulating motor control and reward behaviors. This also included the part of the brain with diminished dopamine-producing neurons in Parkinson's disease. A control group of mice then received mock treatment with an empty virus or an irrelevant antisense sequence.

Researchers subsequently investigated the treated mice in which, a small subset of astrocytes was observed to convert into neurons. This increased the number of neurons by approximately 30 percent and the dopamine levels could be restored to a level comparable to that in normal mice. Subsequently, researchers demonstrated the growth of the neurons and they transmitted their processes into other parts of brain. The control mice did not show any change.

Further, the treated mice returned to normal by two different measures of limb movement and response, within three months after a single treatment. Most importantly they remained completely free 
from symptoms of Parkinson's disease for the rest of their lives, while the control mice showed no improvement.

This potentially game changing new strategy for treating neurodegenerative disorders shows immense promise to help even those with advanced disease and also test this approach as a treatment for Parkinson's disease for other diseases where neurons are lost, such as Alzheimer's and Huntington's diseases and stroke.

\section{Agriculture and Food Science}

\section{Transgenic rice containing anti- hypertensive peptides}

It is known that a major risk factor for cardiovascular disease and stroke is high blood pressure, which is also known as hypertension. Angiotensin Converting Enzyme (ACE) inhibitors belong to a common class of synthetic drugs used for blood pressure regulation to treat hypertension. A challenge with the use of ACE inhibitors is often encountered that is associated with the unpleasant side effects that include dry cough, headache, skin rashes and kidney impairment.

An alternative route is using natural ACE inhibitors that are found in some foods, for example, milk, eggs, fish, meat and plants. Natural ACE inhibitors might be a better choice because they have fewer side effects. However, the challenging part is purifying large amounts of these ACEinhibitory peptides from foods, which is equally expensive and time-consuming.

Researchers from China and Japan have shown a process of extraction of multiple antihypertensive peptides from the transgenic rice seed. Their research was recently published in the Journal of Agriculture and Food Chemistry (Hypotensive Activity of Transgenic Rice
Seed

Accumulating

Multiple

Antihypertensive Peptides, Journal of Agricultural and Food Chemistry, 2020; DOI: 10.1021/acs.jafc.0c01958).

In their study, researchers introduced a gene to rice plants that consisted of nine ACE-inhibitory peptides and a blood-vesselrelaxing peptide linked together. This confirmed that the plants made of high levels of the peptides. Subsequently, total protein (including the peptides) was extracted from the transgenic rice and researchers administered them to rats. Upon administration of the peptides, hypertensive rats showed a reduction in blood pressure, while rats treated with wild-type rice proteins did not show any change in blood pressure after two hours of treatment.

Further, treatment of rats over a 5week period with flour from the transgenic rice showed reduced blood pressure. The reduction of blood pressure was in effect for an extended period of one week later. It is noteworthy that the treated rats did not show any obvious side effects including growth, development or blood biochemistry. Researchers also noted that if these peptides were to exhibit the same effects in humans, a 150-pound adult would be needed to eat only about half a tablespoon of the special rice 
daily to prevent and treat hypertension. This work paves the way to potential breakthroughs in developing alternative source of natural antihypertensive agents.

\section{COVID-19 and Blood Clots}

\section{SARS-CoV-2 can induce functional changes in blood platelets making them hyperactive}

Researchers believe that it is vital to understand the pathogenesis of coronavirus disease 2019 (COVID-19) get insights into thrombotic complications in patients with COVID-19. These complications can contribute to organ failure and mortality. Especially, blood clotting is of major concern. For example, it has been found that patients with severe COVID-19 present with hemostatic abnormalities that mimic disseminated intravascular coagulopathy associated with sepsis exhibit increased risk of thrombosis rather than bleeding.

In a recent study of major impact, researchers addressed the issue of blood clotting and examined platelet gene expression and functional responses in acutely ill patients with COVID-19 that were compared to match healthy donors. They observed changes in blood platelets that were triggered by COVID-19. According to the researchers, this could contribute to the onset of heart attacks, strokes, and other serious cardio vascular complications in some patients who have the disease.

Researchers attributed the changes in blood platelets to the inflammatory proteins that were produced during infection. They argued that this inflammation can significantly alter the function of platelets, making them 'hyperactive' and more prone to form dangerous and potentially deadly blood clots. Their study was recently published in Blood (Platelet Gene Expression and Function in COVID-19 Patients, Blood, 2020; DOI: 10.1182/blood.2020007214).

A differential gene analysis was employed to study SARS-CoV-2 that confirmed the virus triggered genetic changes in platelets. Researchers observed that COVID-19 platelets aggregated more readily. It was also observed how these changes significantly altered platelets and how the platelets interacted with the immune system. This likely contributed to inflammation of the respiratory tract that might result in more severe lung injury.

Researchers further stated that pretreating platelets from SARS-CoV-2 infected patients with aspirin could prevent this hyperactivity. This study sheds important new lights on the alteration of platelet gene expression and increase in functional responses that can happen during SARSCoV-2 infection. Compiled and Edited by

\section{Dr. Megha Agrawal \& Dr. Shyamasri Biswas}

Co Editors-in-Chief 


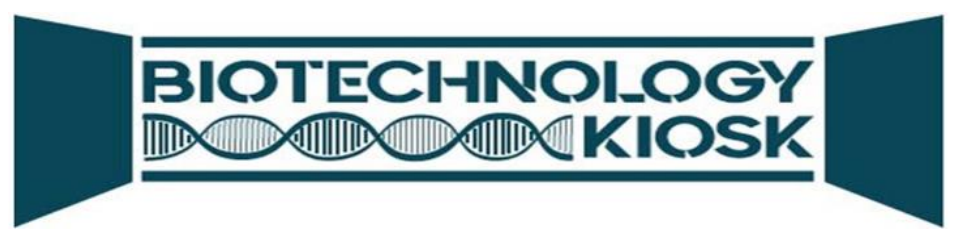

\section{Biotech and Pharma Industry Roundup}

COVID-19 vaccine being jointly developed by Pfizer and BioNTech's shows positive data

Pfizer (New York based) and BioNTech (Germany based) pharma companies recently announced positive results obtained from the preliminary data from the most advanced of four of its vaccine candidates against SARS-CoV-2. The vaccine program (BNT162) is focusing on at least four vaccines, in which each a different combination of mRNA format and target antigen is employed for each vaccine candidate. The preliminary data, which is announced is for BNT1621b1. This vaccine encodes an optimized SARS-CoV-2 receptor binding domain (RBD) antigen [Source: https://www.biospace.com/].

\section{A $\$ 900$ million non-viral gene therapy collaboration between Takeda and Carmine}

In a recent partnership, Cambridge, Massachusetts-based Carmine Therapeutics agreed to a research collaboration deal worth $\$ 900$ million with Japan's Takeda Pharmaceutical to develop and commercialize non-viral gene therapies for two rare diseases. Carmine's REGENT technology platform has been shown to be promising for red blood cell extracellular vesicles (RBCEVs). The technology is based on engineered O-type blood cells to carry the RNA payload to the target cells [Source: https://www.biospace.com/].

\section{A New H1N1 Strain from China could possibly trigger another global pandemic}

Researchers have observed that another pandemic could be building in China with a new strain of the H1N1 swine flu that has been reported already jumped to humans. The new strain, G4 EA H1N1 was revealed to emerge on China's pig farms According to the researchers, this strain has all the hallmarks of a pandemic virus, which is a recently emerged genotype 4 (G4) reassortant Eurasian avian-like (EA) $\mathrm{H} 1 \mathrm{~N} 1$ virus that bears 2009 pandemic (pdm/09) and triple-reassortant (TR)-derived internal genes [Source: https://www.biospace.com/].

\section{FDA approves Pfizer and Merck KGaA's Bavencio for Urothelial Cancer}

The U.S. Food and Drug Administration (FDA) recently approved Bavencio (avelumab) that is ministered for maintenance treatment of locally advanced or metastatic urothelial carcinoma (UC) that 
has not progressed after first-line platinumcontaining chemotherapy. Merck KGaA, Darmstadt, Germany and Pfizer codeveloped Bavencio as an anti-PD-L1 checkpoint inhibitor co-developed via their EMD Serono, a business unit of the two companies

[Source:

https://www.biospace.com/].

Menlo Therapeutics' ZILXI ${ }^{\mathrm{TM}}$ (minocycline) topical foam, $1.5 \%$ receives FDA approval for the treatment of inflammatory lesions of rosacea in adults

Rosacea is known as a diverse skin condition. The most commonly symptoms of rosacea are deep facial redness, spider veins (telangiectasia) and acne-like inflammatory lesions (papules and pustules). Menlo Therapeutics Inc., which is a specialty pharmaceutical company focused on therapies to address unmet needs in dermatology recently announced the approval of ZILXI ${ }^{\mathrm{TM}}$ (minocycline) topical foam, $1.5 \%$ by the FDA. ZILXI ${ }^{\mathrm{TM}}$ is used for the treatment of inflammatory lesions of rosacea in adults. ZILXI was developed as FMX103 by Menlo's wholly-owned subsidiary Foamix Pharmaceuticals Ltd. ("Foamix"), is considered the first minocycline product of any kind to be approved by the FDA for use in rosacea. This FDA approval is considered very encouraging news for clinicians and patients seeking options for this difficult to treat skin disorder [Source: https://www.biospace.com/].

\section{Price set for COVID-19 drug remdesivir}

In a recent announcement, the manufacturer of the drug remdesivir, Gilead said it will charge between $\$ 2,340$ and $\$ 3,120$ for a typical course of treatment with its COVID-19 drug remdesivir. In recent clinical trials, this drug has been shown to speed the recovery of patients hospitalized with the infectious disease. In the plan announced by Gilead, it will offer remdesivir to governments in developed countries at a price of $\$ 390$ per vial. However, in the U.S., private insurers, as well as government health programs like Medicare that don't purchase drugs directly, will pay $\$ 520$ per vial [Source: https://www.biopharmadive.com/].

\section{Meningococcal Vaccines expected to touch US\$ 9 billion by 2026}

Bacteria Neisseria meningitides causes meningococcal disease. This disease occurs throughout the world especially in the developing world. Typical symptoms include inflammation in the membranes of the brain and spinal cord which is characteristic of meningitis. The meningococcal vaccines market is pretty vast with a lot of potential to make its footprints even larger in the future that is expected to reach $\$ 9$ billion by 2026 . This vaccine exists in the market and doing a great business due to its utility and need for preventing the incidence of this deadly disease

[Source: 
Novartis

partners

Massachusetts Eye \& Ear hospital to manufacture coronavirus vaccine

In a recent announcement, Novartis' AveXis division said that it will manufacture a coronavirus vaccine partnering with Massachusetts Eye and Ear Hospital. This partnership is supposed to pave the way for the academic institution to take advantage of the technology that has delivered the gene therapy Zolgensma to spinal muscular atrophy patients. It is expected that AveXis will begin manufacturing the vaccine as soon as possible with the partnering hospital expecting to begin a Phase 1 trial in humans in the second half of 2020 [Source: https://www.biopharmadive.com/).

\section{WHO proposes plan to deliver 2 billion coronavirus vaccine doses}

The World Health Organization, together with partner organizations announced an ambitious plan to secure 2 billion doses of coronavirus vaccines by the end of 2021 . This plan is aimed to ensure high-risk groups around the world that can have access to any vaccine that's successfully developed [Source: https://www.biopharmadive.com/)].

\section{Large scale phase 2 and phase 3 trials are underway for coronavirus vaccine}

Late-stage clinical trials are underway involving tens of thousands of people for coronavirus vaccine development. Phase 2 and phase 3 trials are being prepared in the
U.S., Europe and also other regions due to the fact that the pandemic's heaviest impact has begun to shift to the Southern Hemisphere. This large scale clinical trials correspond to an important transition from an early safety studies of coronavirus vaccines that involved several dozens to hundreds of healthy volunteers. But considering the uniqueness of this global pandemic that will require safety and effectiveness of a treatment to be potentially given to tens of millions of people globally, massive trials spanning many countries are required. To this end, a phase 2 study of a vaccine being developed by the University of Oxford and AstraZeneca aims to recruit 10,260 adults and children in the U.K. In addition, the British drug maker is planning a phase 3 trial in the U.S. involving about 30,000 people [Source: https://www.biopharmadive.com/)].

\section{Investors pouring cash to counter cancer genes}

It is known for years that a family of genes that, when mutated, turn regular cells cancerous. There has been recent progress in developing drugs that can effectively silence those genes. This has fueled investor optimism in companies going after these genes that are known as RAS. The most recent example of investments comes from a California based biotech company named Revolution Medicines that has raised \$238 million through an initial public offering. RAS genes are known to make special proteins that regulate how a cell grows, specializes and divides. One of these proteins, K-ras, has drawn a particularly large amount of attention for R\&D. and Amgen, the country's largest biotech has released data showing an 
experimental drug appeared to stabilize disease in a small group of lung cancer patients with KRAS gene mutations. This has further fueled extensive R\&D in this area [Source: https://www.biopharmadive.com/)].

\section{Roche presents biomarker for checkpoint block blockade}

Researchers at Swiss pharma giant Roche AG have demonstrated a subpopulation of dendritic cells that determines how cancer patients respond to immune checkpoint inhibitors [Source: https://europeanbiotechnology.com/].

\section{Dutch Biotech Company HALIX B.V.} to produce vaccines against COVID19

Dutch CDMO HALIX B.V. has entered in a research consortium coordinated by the University of Oxford, to provide GMPcompliant production of Vaccitech Ltd's COVID-19 vaccine (ChAdOx1 nCoV-19) targeting the viral spike protein [Source: https://european-biotechnology.com/].

\section{SARS-CoV2 antibody tests might not be suitable for individual diagnosis}

An international research consortium in Europe has provided data that demonstrate that SARS-CoV-2 antibody tests are only useful for population-based analyses and might not work for individual diagnosis. [Source: https://europeanbiotechnology.com/].

\section{FDA rejects AbbVie's eye drug}

The FDA rejected the eye drug, abicipar proposed by AbbVie that was supposed to challenge market-leading drugs like Regneron's Eylea. In clinical trials, the inner eye inflammation that was seen to appear contributed to the FDA rejection [Source: https://www.biopharmadive.com/)].

\section{EC pledges $€ 4.9 \mathrm{bn}$ to grant access to medicines}

Under the Coronavirus Global Response Framework, the European Commission recently announced to allocate further $€ 4.9 \mathrm{bn}$ to assure access to COVID-19 countermeasures for poor countries [Source: https://european-biotechnology.com/].

\section{No beneficial effect of the antiviral HIV treatment lopinavir-ritonavir in patients hospitalized with COVID-19}

Recent clinical data from the UK's RECOVERY trial demonstrated no clinical benefit from use of lopinavir-ritonavir in hospitalised COVID-19 patients [Source: https://european-biotechnology.com/]. 


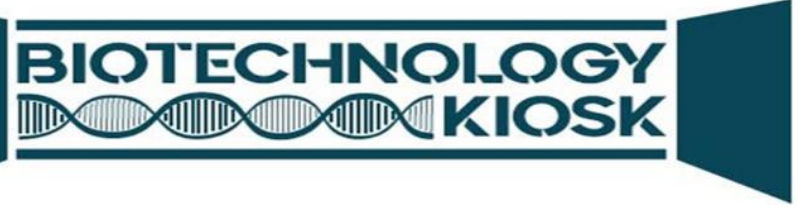

For all production related questions or sending your ads, please email or call our production department: E-mail: sales@biotechkiosk.com; Phone: 386-518-9411.

\section{THANK YOU!}

